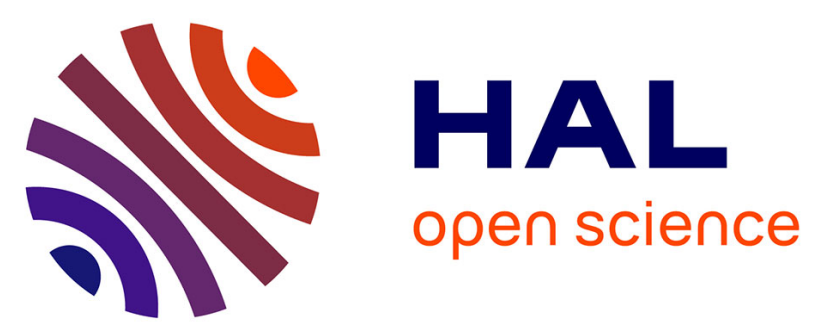

\title{
Tissue- and paralogue-specific functions of acyl-CoA-binding proteins in lipid metabolism in $\mathrm{C}$. elegans
}

Ida Elle, Karina Trankjær Simonsen, Louise Cathrine Braun Olsen, Pernille Kirstine Birck, Sidse Ehmsen, Simon Tuck, Thuc Timothy Le, Nils J. Faergeman

\section{To cite this version:}

Ida Elle, Karina Trankjær Simonsen, Louise Cathrine Braun Olsen, Pernille Kirstine Birck, Sidse Ehmsen, et al.. Tissue- and paralogue-specific functions of acyl-CoA-binding proteins in lipid metabolism in C. elegans. Biochemical Journal, 2011, 437 (2), pp.231-241. 10.1042/BJ20102099 . hal-00605255

\section{HAL Id: hal-00605255 \\ https://hal.science/hal-00605255}

Submitted on 1 Jul 2011

HAL is a multi-disciplinary open access archive for the deposit and dissemination of scientific research documents, whether they are published or not. The documents may come from teaching and research institutions in France or abroad, or from public or private research centers.
L'archive ouverte pluridisciplinaire HAL, est destinée au dépôt et à la diffusion de documents scientifiques de niveau recherche, publiés ou non, émanant des établissements d'enseignement et de recherche français ou étrangers, des laboratoires publics ou privés. 


\section{TISSUE- AND PARALOGUE-SPECIFIC FUNCTIONS OF ACYL-COA-BINDING PROTEINS IN LIPID METABOLISM IN C. ELEGANS}

Ida Coordt Elle ${ }^{*}$, Karina Trankjær Simonsen ${ }^{* \dagger}$, Louise Cathrine Braun Olsen ${ }^{*}$ 'Pernille Kirstine Birck $^{*}$, Sidse Ehmsen*, Simon Tuck ${ }^{\ddagger}$, Thuc T. Le ${ }^{\S}$, Nils Joakim Færgeman ${ }^{*}$

*Department of Biochemistry and Molecular Biology, University of Southern Denmark, Odense, Denmark

${ }^{\dagger}$ Present address: University of British Columbia, Wine Research Centre, Vancouver, B.C., Canada

‡Umeå Centre for Molecular Medicine, Umeå University, Umeå, Sweden

${ }^{\S}$ Nevada Cancer Institute, Las Vegas, Nevada, USA

\section{Corresponding author:}

Nils Joakim Færgeman nils.f@bmb.sdu.dk tel: 45 65502453; Fax: 4565502467.

Department of Biochemistry and Molecular Biology, University of Southern Denmark

Campusvej 55, 5230 Odense M, Denmark. 


\section{Synopsis}

Acyl-CoA binding protein (ACBP) is a small, primarily cytosolic protein that binds acyl-CoA esters with high specificity and affinity. ACBP has been identified in all eukaryotic species, indicating that it performs a basal cellular function. However, differential tissue expression and the existence of several ACBP paralogues in many eukaryotic species indicate that these proteins serve distinct functions. The nematode Caenorhabditis elegans expresses seven ACBPs; four basal forms and three ACBP-domain proteins. We find that each of these paralogues is capable of complementing growth of ACBP-deficient yeast cells, and that they exhibit distinct temporal- and tissue expression patterns in C. elegans. We have obtained loss-of-function mutants for six of these forms. All single mutants display relatively subtle phenotypes; however we find that functional loss of ACBP-1 leads to reduced triglyceride levels and aberrant lipid droplet morphology and number in the intestine. We also show that worms lacking ACBP-2 show a severe decrease in the $\beta$-oxidation of unsaturated fatty acids. A quadruple mutant, lacking all basal ACBPs, is slightly developmentally delayed, displays abnormal intestinal lipid storage, and increased $\beta$-oxidation. Collectively, the present results suggest that each of the ACBP paralogues serves a distinct function in C. elegans.

Short title: ACBP functions in C. elegans

Keywords: ACBP, lipid storage, transport, $\beta$-oxidation, $C$. elegans.

Abbreviations: ACBD, acyl-CoA binding domain; ACBP, acyl-CoA binding protein; BHT, butylated hydroxytoluene; C/EBP, CCAAT-enhancer binding protein; $C$. elegans, Caenorhabditis elegans; CARS, Coherent Anti-stokes Raman Scattering microscopy; DBI, diazepam binding inhibitor; $\mathrm{ECH}$, enoyl-CoA hydratase; FAME, fatty acid methyl ester; HNF4 $\alpha$, hepatic nuclear factor $4 \alpha, \mathrm{KLF}$, Krüppel-like factor; MAA-1, membrane-associated ACBP; NHR, nuclear hormone receptor; PPAR, peroxisome proliferator-activated receptor; qRT-PCR, quantitative real-time PCR; SBP/SREBP, sterol regulatory-element binding protein; TAG, triacylglycerol; TCA, trichloroacetid acid; TGF- $\beta$, transforming growth factor $\beta$; TOR, Target Of Rapamycin; YNB medium, yeast nitrogen base medium.

\section{Introduction}

Fatty acid biosynthesis and fatty acid degradation are co-ordinately regulated by environmental and metabolic cues in both prokaryotes and eukaryotes. In Eschericia coli the transcription factor FadR co-ordinately regulates the expression of genes encoding fatty acid biosynthetic and catabolic enzymes via direct interaction with acyl-CoA esters [1]. In mammals, transcription factors such as CCAAT-enhancer binding proteins (C/EBP), sterol regulatory element-binding protein-1 (SREBP-1c), hepatic nuclear factor 4a (HNF4 $\alpha$ ), peroxisome proliferator-activated receptors (PPAR), and Krüppel-like factors (KLF) have been recognized as important regulators of lipid metabolism [2]. Homologues of the majority of these transcription factors have been identified in invertebrates such as Drosophila melanogaster and C. elegans and have been shown to function much like their mammalian counterparts in regulating lipid synthesis, -accumulation, and -catabolism (reviewed in [3-4]). In particular, because of its genetic versatility and functional analogy to higher organisms, $C$. elegans has during the past decade proven to be a powerful model to identify and understand novel genes and signalling pathways regulating lipid homeostasis. These include signalling through the Target Of Rapamycin (TOR)-, insulin-, TGF- $\beta-$, and serotonin pathways (reviewed in [3]). Changes in the activity of these signalling pathways eventually affect the 
level or activity of metabolic enzymes involved in the utilization of various lipid species. The first step in the metabolism of fatty acids is carried out by acyl-CoA synthetases, which catalyze the formation of fatty acyl-CoA esters [5]. This step is recognized as a key control point in the regulation of lipid homeostasis, since fatty acid activation is obligatory for biosynthesis of glycerolipids, phospholipids, cholesterol esters, and complex lipids such as ceramides and sphingolipids but also for degradation of fatty acids via $\beta$-oxidation. AcylCoA synthetases are known to be required to support fatty acid import and growth in bacteria [6] and in the yeast Saccharomyces cerevisiae [7], for normal neuronal development in fruit flies [8], for normal fat storage [9] and cuticle surface barrier function in C. elegans [10], and for metabolic channelling of fatty acyl-CoA in mammals [11].

However, the biophysical properties of fatty acyl CoAs and the fact that they also are recognized as important cellular regulators of ion channels, enzyme activities, and membrane fusion [12] necessitate careful control of their availability to maintain cellular homeostasis. It is therefore anticipated that cellular acyl-CoA binding proteins (ACBP) bind, sequester, and transport fatty acyl-CoAs to acyl-CoA-utilizing enzymes and modulate their regulatory functions [12]. The ACBP family comprises basal acyl-CoA binding proteins containing only the ACBP domain and larger proteins that contain an N-terminal acyl-CoA binding domain (ACBD) as well as other domains. The prototypical basal ACBP was originally identified in bovine liver and later found to be identical to diazepam binding inhibitor (DBI) [13], which according to standardized gene nomenclature is also designated ACBD1 (henceforth LACBP/DBI will be termed ACBD1). ACBD1 is a ubiquitously expressed $10 \mathrm{kDa}$ protein of 86 amino acids, which localizes primarily to the cytosol but has also been found to localize to the Golgi, ER, and the nucleus in both human and bovine epithelial cells [14]. ACBD1 or the gene encoding it has been identified in all eukaryotic species examined, and based on both the primary, secondary, and tertiary structure is also highly conserved in eukaryotes [15]. The three-dimensional structure shows that ACBD1 consists of four $\alpha$-helices, which fold as a skew up-down-down-up helix bundle [16]. This arrangement yields a four-helical interface creating a bowl-like structure to specifically accommodate binding of fatty acyl-CoA with high affinity $\left(\mathrm{K}_{\mathrm{d}}\right.$ is approximately $\left.1 \mathrm{nM}\right)$ [17].

Although the basal ACBP displays the hallmarks of a housekeeping gene in mammals [18] and hence has been proposed to serye a basal function common to all cells, its precise cellular role is yet to be elucidated. Targeted knockout of ACBD1 in mice has been reported to cause pre-implantation embryonic lethality in mice [19], consistent with an essential function to support cellular survival and growth in human cell lines [20] and in Trypanosoma brucei [21]. Depletion of acyl-CoA binding protein (Acb1) in Saccharomyces cerevisiae causes severe growth retardation, perturbed organelle function and assembly, and reduced levels of very-long chain fatty acids, ceramides, and sphingolipids [22-23]. Other studies, however, have been unable to confirm an essential function of ACBD1. For example, mice carrying an approximately $400 \mathrm{~kb}$ deletion including ACBD1 on chromosome 1 have sparse matted hair and sebocyte hyperplasia, likely caused by altered synthesis of triacylglycerol (TAG) [24]. In 3T3-L1 pre-adipocytes, antisense-mediated knockdown of ACBD1 results in impaired adipocyte differentiation, and reduced accumulation of TAG [25]. In keeping with a function in TAG synthesis, over-expression of ACBD1 in McA-RH7777 rat hepatoma cells [26] and in transgenic mice [27] has previously been shown to result in increased intracellular TAG accumulation. Moreover, knockdown of ACBD1 in human HepG2 cells suppresses the expression of a number of genes involved in lipid biosynthesis [28]. In experiments with cellfree systems, ACBD1 has many different activities including the ability to desorb acyl-CoAs embedded in membranes to deliver them to acyl-CoA-utilizing systems such as $\beta$-oxidation 
and glycerolipid synthesis, to protect acyl-CoA from hydrolysis, and to suppress the inhibitory effect of acyl-CoA on a variety of enzymes including acetyl-CoA carboxylase, acyl-CoA synthetase, adenine nucleotide translocase, acyl CoA:cholesterol acyl transferase, carnitine-palmitoyl transferase, and fatty acid synthase (reviewed in [12, 15]).

In the present work we have examined the function of six ACBP paralogues in fat storage and fatty acid oxidation in C. elegans. We demonstrate that they are functional as acyl-CoA binding proteins, display distinct tissue expression patterns, and have specific functions in lipid homeostasis

\section{Materials and Methods}

Strains: Worms were cultured using standard methods [29]. The following strains were provided by the Caenorhabditis elegans Genetics Center: Wild-type N2 Bristol and RB1464 acbp-5(ok1692). The following strains were provided by the National Bioresource Project for the Experimental Animal "Nematode C. elegans", Japan: acbp-2/ech-4(tm3573), acbp4(tm2896), and acbp-6(tm2995). All deletion mutants were outcrossed at least seven times to the N2 Bristol strain prior to use. Worms were kept at $20^{\circ} \mathrm{C}$ on standard NGM plates seeded with OP50 culture.

Isolation of deletion alleles: The deletion alleles were isolated by screening a $C$. elegans deletion library generated with trimethyl-psoralen and UV-light. The $a c b p-1(s v 62)$ deletion allele was identified by PCR using the outer primers 5'-GTACTGTGTTCGCTGAGGATG3' and 5'-GGGCTCCCGATCAAGAGTTTC-3' and the poison primers 5'GTCTTGAGGGTCTTAACGGTG-3' and 5'-GAATGATGAGCTTCTCAAGCTC-3' for the first round of PCR. Nested PCR was carried out using the primers 5'GATCGAAACCTTGCAGCTACAG-3' and 5'CAGATCACTCGGAACAGGGAACATG$3^{\prime}$. Sequencing determined the $s v 62$ allele to be a 593 bp deletion removing all of exon 1 and 485 bp upstream of the start codon (C44E4 coordinates; 30623-31216). In subsequent genotyping experiments, the $s v 62$ mutant allele was identified using the primers R1 5'GTCTTGAGGGTCTTAACGGTG-3', 5'GGCTGCAGGGGCTCCCGATCAAGAGTTTC-3' and F2 'CAAAATGACCCTCTCGGTAAGC-3' in a duplex PCR reaction. The $a c b p-3(s v 73)$ deletion allele was identified by $P C R$ using the outer primers 5'ATGACGTCTTGTTCACGGGAAG-3' and 5'-CACAATCATCCGTTCCTACTCG-3' and the poison primers 5'-GATGATTTCCACAGCAGCGTCG-3' and 5'CAGGTACGTTGGACTTTGATTC-3' for the first round of PCR. Nested PCR was carried out using the primers F1 5'-TTAGGTCAACAGCAGCAGCCC-3' and R1 5'CACGCGGTCATGACTCATTTG-3'. Sequencing determined the $s v 73$ allele to be a $490 \mathrm{bp}$ deletion removing exon 1 and exon 2 (F47B10 coordinates: 15282-15772). In subsequent genotyping experiments the $s v 73$ mutant allele was identified using the duplex primers R1 5'CACGCGGTCATGACTCATTTG-3', F1 5'-TTAGGTCAACAGCAGCAGCCC-3' and F2 5'-CATCGAGAGAAAGAAGTGGTC-3'.

Generation of GFP reporter fusion constructs and transgenic animals: The acbp genomic DNA, except for acbp-6, including at least one kilobase of upstream 5' sequence was amplified by PCR (primers and conditions available upon request) and subcloned into pPD95.77 by using PstI and XmaI fusing the coding sequence in-frame to (S65C) green fluorescent protein (GFP) to generate ACBP::GFP. The transgenic lines were generated by co-injecting the reporter constructs together with pRF4 (rol-6 (su1006)) into N2 hermaphrodites. Both plasmids were injected at a concentration of $80 \mathrm{ng} / \mu \mathrm{L}$ according to standard protocols. Tissue-specific expression of ACBP-6 was examined in 
sEx14395[rCesY17G7B.1::GFP + pCeh361] transgenic animals, obtained from Caenorhabditis elegans Genetics Center. Worms were mounted in M9 buffer containing Tetramisol $(10 \mu \mathrm{M})$ (Sigma-Aldrich, St. Louis, Montana, USA) on a 2\% agar pad on a microscope slide and covered with a coverslip and analyzed by confocal microscopy on an LSM 510 META microscope (Carl Zeiss MicroImaging Inc., Germany). Primary image analysis was performed using LSM Image Browser (Carl Zeiss Microlmâging Inc., Germany).

Cloning and ectopic expression in Saccharomyces cerevisiae: The open reading frames encoding ACBP-1 to ACBP-6 from $C$. elegans were amplified by RT-PCR from total RNA isolated from the Bristol $\mathrm{N} 2$ strain. The yeast ACBP gene $(A C B 1)$ was amplified from genomic DNA from Saccharomyces cerevisiae. Primer sequences are available upon request. All PCR amplicons were purified and digested with $X b a \mathrm{I}$ and $B a m H I$ and inserted into

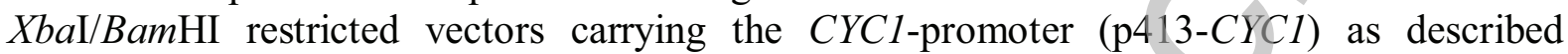
previously [30]. Each insertion was confirmed by DNA sequencing. Plasmids (with and without insertions) were transformed into either wild-type yeast cells (Y700) or yeast cells expressing $A C B 1$ under the control of the GAL1 promoter as described [22] and selected on YNB plates without histidine supplemented with galactose (2\%). To examine complementation of growth, transformed yeast cells were inoculated at $30{ }^{\circ} \mathrm{C}$ in supplemented minimal YNB medium without histidine containing glucose $(2 \%)$. Cells were grown for $24 \mathrm{~h}$, diluted into fresh medium to an $\mathrm{OD}_{600}$ of $0.05-0.1$ and growth was monitored at $\mathrm{OD}_{600}$ for the time indicated.

RNA isolation, cDNA synthesis, and quantitative real-time PCR: Total RNA was extracted from four independent synchronized worm populations of each strain as described (51). cDNA was synthesized from $1 \mu \mathrm{g}$ total RNA as previously described (52). Quantitative realtime PCR (qRT-PCR) was performed on an ABI PRISM 7700 RealTime PCR-machine (Applied Biosystems, Carlsbad, California, USA) or Stratagene MXPro 3000 (Agilent Technologies, Santa Clara, California, USA) using 2x SYBR Green JumpStart ${ }^{\mathrm{TM}}$ Taq ReadyMix $^{\text {TM }}$ and Sigma Reference Dye (Sigma-Aldrich, St. Louis, Montana, USA) as described by the manufacturer. PCR reactions were performed in $25 \mu 1$ reactions containing $1.5 \mu \mathrm{l}$ of diluted cDNA. Reactions were incubated at $95{ }^{\circ} \mathrm{C}$ for 2 min followed by 40 cycles of $95{ }^{\circ} \mathrm{C}$ for $15 \mathrm{~s}, 60{ }^{\circ} \mathrm{C}$ for $45 \mathrm{~s}$ and $72{ }^{\circ} \mathrm{C}$ for $45 \mathrm{~s}$. All reactions were performed in duplicates and normalized to the level of the $t b p-1$ gene (encoding a TATA-binding protein, the $C$. elegans orthologue of the human TATA-box-binding protein). Primers for qRT-PCR were designed using Primer Express version 2.0 (Applied Biosystems, Carlsbad, California, USA) and designed so the efficacies of each of the ACBP primer pairs were the same.

Lifespan analysis: Worms were synchronized and grown to the young adult stage (L4 + 1 day; day 0 of lifespan). 120 worms $(10 \times 12)$ were transferred to seeded NGM plates and kept at $20^{\circ} \mathrm{C}$. Worms were scored every or every other day and were counted as "dead" when they no longer responded to gentle prodding with a worm pick (end of lifespan). Worms were transferred to fresh plates every other day during their reproductive period and every $\sim$ four days after this. Data were analyzed according to the Log-rank (Mantel-Cox) test and survival curves were generated using GraphPad Prism ver. 5 (GraphPad Software, La Jolla, California, USA).

Coherent Anti-Stokes Raman Scattering microscopy: CARS microscopy was performed as described by Le et al. 2010 [31].

Enzymatic determination of triglyceride levels: Synchronized L4 stage worms were washed off five $9 \mathrm{~cm}$ plates and washed three times in $0.9 \% \mathrm{NaCl}$. Worms were left for $20 \mathrm{~min}$ to empty their intestines and washed once in sterile water. Worms and water (total volume: 500 
$\mu \mathrm{L}$ ) were transferred to $15 \mathrm{~mL}$ glass tubes, and from this, $100 \mu \mathrm{L}$ were transferred to $1.5 \mathrm{~mL}$ centrifuge tubes for protein determination. Lipids were extracted according to Bligh and Dyer [32]. Samples were dried under nitrogen, redissolved in lipoprotein lipase buffer as described in [33], and sonicated for $30 \mathrm{sec}$ in a bath sonicator (Branson 2510; Branson, Cleveland, Ohio, USA) and left on an orbital shaker overnight at room temperature protected from light. Subsequently, samples were sonicated $3 \times 30 \mathrm{sec}$ in a water bath sonicator prior to enzymatic determination of triglyceride levels using the AdipoSight kit ${ }^{\circledR}$ from Zen-Bio (Zen-Bio, Inc., Research Triangle Park, North Carolina, USA). Triglyceride content of samples was determined by comparison to a standard curve made from triolein standards (treated as samples) and normalized to protein content.

Determination of $\beta$-oxidation rates: To measure fatty acid oxidation, we modified an assay previously used to determine fatty acid oxidation in mammalian cells [34] in which oxidation of $\left[9,10-{ }^{3} \mathrm{H}\right]$ fatty acid results in formation of ${ }^{3} \mathrm{H}_{2} \mathrm{O}$. Synchronized L4 stage worms were washed off five to ten $9 \mathrm{~cm}$ plates into Falcon tubes and washed three times in $0.9 \% \mathrm{NaCl}$. Worms were left for $20 \mathrm{~min}$ to empty their intestine and washed once in S-basal. Worms were allowed to settle at the bottom of the tubes, and $780 \mu \mathrm{L}$ were transferred to a $2.0 \mathrm{~mL}$ centrifuge tube. From this tube, $260 \mu \mathrm{L}$ were transferred to another tube along with $260 \mu \mathrm{L}$ S-basal. All samples were thereby measured in duplicate with one containing approximately twice as many worms as the other. From each sample, $20 \mu \mathrm{L}$ were transferred to $1.5 \mathrm{~mL}$ centrifuge tubes, $80 \mu \mathrm{L}$ water were added, and the tubes were stored at $-80{ }^{\circ} \mathrm{C}$ for subsequent protein determination. Blanks, containing only S-basal, were treated as samples. $\left[9,10-{ }^{3} \mathrm{H}(\mathrm{N})\right]$ oleic acid $(15 \mathrm{Ci} / \mathrm{mmol})$ or $\left[9,10-{ }^{3} \mathrm{H}(\mathrm{N})\right]$ palmitic acid $(30 \mathrm{Ci} / \mathrm{mmol}$, Perkin Elmer, Waltham, Massachusetts, USA) was used as source of radioactivity. Oleic acid or palmitic acid was complexed to fatty acid-free BSA in a 4:1 ratio and added to a final concentration of $20 \mathrm{mM}$ (specific activity 67-93 Ci/mol), and samples were incubated end-over-end for one hour at room temperature. After incubation, $10 \% \mathrm{~W} / \mathrm{v}$ TCA $(540 \mu \mathrm{L})$ were added, and the samples were vortexed briefly. Samples were centrifuged at $10000 \mathrm{~g}$ for 5 minutes at room temperature, and the supernatants were transferred to fresh tubes. PBS $(250 \mu \mathrm{L})$ and $5 \mathrm{M}$ $\mathrm{NaOH}(100 \mu \mathrm{L})$ were added, and the samples were loaded onto freshly prepared Dowex 1x8 200-400 MESH CI exchange columns. Samples were eluted using water $(1 \mathrm{~mL})$ into scintillation tubes. The amount of tritiated $\mathrm{H}_{2} \mathrm{O}$ generated was determined by scintillation counting and expressed as pmol oxidized fatty acid per mg protein per min. Data were analyzed using GraphPad Prism ver. 5 (GraphPad Software, La Jolla, California, USA).

Analysis of fatty acid composition by gas chromatography: Synchronized L4 stage worms were washed off five to ten $9 \mathrm{~cm}$ plates and washed three times in $0.9 \% \mathrm{NaCl}$. Worms were left for $20 \mathrm{~min}$ to empty their intestine, washed once in sterile water, resuspended in freshly prepared $2.5 \% \mathrm{H}_{2} \mathrm{SO}_{4}$ in water-free methanol $(1 \mathrm{~mL})$ supplemented with $10 \mu \mathrm{g} / \mathrm{mL}$ butylated hydroxytoluene (BHT), and incubated for five hours at $80{ }^{\circ} \mathrm{C}$. Subsequently, the fatty acid methyl esters (FAMEs) were extracted by the addition of hexane $(0.5 \mathrm{~mL})$ and $\mathrm{H}_{2} \mathrm{O}(1.5 \mathrm{~mL})$. The organic phase was transferred to fresh sample vials and dried under a stream of N2. Each sample was redissolved in hexane $(40-50 \mu \mathrm{L})$, and FAMEs were analyzed by gas chromatography on a Chrompack CP 9002 equipped with a DB-WAX column (Agilent Technologies, Santa Clara, California, USA). The FAMEs were identified by comparison to standards from Larodan Fine Chemicals (Malmö, Sweden). Statistics and comparisons were performed by using Dunnett's t-test.

Protein determination: Samples were diluted in sonication buffer $[10 \mathrm{mM}$ Tris- $\mathrm{HCl} \mathrm{pH} 7.5$, $40 \mathrm{mM} \mathrm{NaCl}](200 \mu \mathrm{L})$ and sonicated $3 \times 30 \mathrm{sec}$ at maximum intensity on a Bioruptor UCD200 (Diagenode, Liege, Belgium). Additional sonication buffer (200 $\mu \mathrm{L})$ and SDS (to $0.1 \%$ ) 
were added, and samples were incubated end-over-end at $4{ }^{\circ} \mathrm{C}$ for one hour. Samples were spun $18000 \mathrm{~g}$ for $5 \mathrm{~min}$ at $4{ }^{\circ} \mathrm{C}$ and protein concentrations were measured using the Qubit Quant-iT Protein Assay kit ${ }^{\circledR}$ according to the manufacturer (Invitrogen, Carlsbad, California, USA).

Sequence Alignment and Phylogenetic Analysis: The amino acid sequences of the open reading frames were initially aligned using the program ClustalX version 1.8.

\section{Results \\ The $C$. elegans genome encodes seven functional acyl-CoA binding proteins, which are expressed in specific tissues}

The $C$. elegans genome encodes seven highly conserved proteins containing an acyl-CoA binding domain. Alignment of the ACBP domains of the $C$. elegans paralogues with human ACBD1 and yeast Acb1 (Fig. 1C) demonstrates that ACBP-1 through -6 and MAA-1 (Membrane-associated ACBP-1) all contain the amino acids required for protein stability and ligand binding [35]. Four of these proteins; ACBP-1, ACBP-3, ACBP-4, and ACBP-6 contain only the ACBP domain, while ACBP-2, ACBP-5, and MAA-1 have an N-terminal ACBP domain as well as other functional domains (Fig. 1), ACBP-2, previously described as $\mathrm{ECH}-4$, which by virtue of an enoyl-CoA hydratase/isomerase $(\mathrm{ECH})$ domain and a predicted $\mathrm{N}$-terminal mitochondrial targeting signal, is likely to be involved in mitochondrial $\beta$ oxidation of fatty acids [36]. ACBP-5 contains two ankyrin repeats, which may mediate interactions with other proteins, as it has been observed for its orthologue in Arabidopsis thaliana ACBP2 [37]. Besides a transmembrane domain, MAA-1 contains a coiled-coil domain. We have previously shown that this paralogue is expressed in the intestine, hypodermis, and oocytes and is involved in endosomal trafficking in C. elegans [30]. Recently, another paralogue, ACBP-7, was identified in the C. elegans genome, however, several key amino acids necessary for ACBP stability and ligand binding are not conserved in ACBP-7 [35], suggesting that this form may not be functional as an acyl-CoA binding protein. Phylogenetic analysis (Fig. 1B) revealed that ACBP-1 is closely related to acyl-CoA binding protein from Saccharomyces cerevisiae Acb1 and ACBD1, while these are more distantly related to ACBP-2, ACBP-3, ACBP-4, ACBP-5, and MAA-1, which phylogenetically group together.

We have previously shown that ectopic expression of either yeast acyl-CoA binding protein (Acb1) or MAA-1 complement the slow-growth phenotype of Acb1-depleted yeast cells, and that disruption of ligand binding impairs its ability to complement growth [30]. We ectopically expressed each of the C. elegans ACBPs in yeast cells depleted of Acb1, and monitored growth over time. We verified our previous findings that ectopic expression of Acb1 complements the growth phenotype of Acb1-depleted cells and that the complementing capability depends on its ability to bind acyl-CoA esters, as mutation of tyrosine 28 and lysine 32 (previously shown to be required for ligand binding) to alanines [35, 38] fully ablated the complementing properties (Fig. 2A). Notably, we found that each of the $C$. elegans ACBP paralogues was able to rescue the slow growth phenotype when expressed in Acb1-depleted yeast cells (Fig. 2B), suggesting that ACBP-1 to ACBP-6 and MAA-1 are functional as acyl-CoA binding proteins when expressed in Saccharomyces cerevisiae.

To confirm that the ACBP genes are expressed in C. elegans we isolated total RNA from N2 animals both at the L1 and the L4 stage, and employed qRT-PCR to quantitatively address the expression level of each paralogue. At the L1 stage $a c b p-3$ is the most abundantly expressed gene, while $a c b p-1$ and $a c b p-2$ are expressed at lower levels (Fig. 3). The expression levels of $a c b p-4, a c b p-5, a c b p-6$, and maa-1 are significantly lower compared to 
than that of $a c b p-3$. At the L4 stage, the expression level of $a c b p-1$ is increased 5-fold compared to the L1 stage, while the relative expression levels of the other acbp genes remain unaltered.

To characterize the spatial expression of the $a c b p$ genes in $C$. elegans we constructed transgenic lines expressing translational $g f p$ fusions of each of the individual $a c b p$ genes, except for a transgenic line carrying a transcriptional $g f p$ fusion under the control of the $a c b p$ 6 promoter, which we obtained from The Caenorhabditis Genetics Center. The upstream region and the entire coding region, which are assumed to encompass the regulatory region of each $a c b p$ gene, were amplified and cloned into pPD95.77. Of the short ACBP isoforms, ACBP-1::GFP is predominantly found in the intestine at the L4 stage (Fig. 4), while ACBP3::GFP can be observed in the hypodermis, body wall muscles, and in the pharynx (Fig. 4). In line with the quantitative PCR results, ACBP-4::GFP and ACBP-6::GFP are only weakly expressed. ACBP-4::GFP is found to be specifically localized to granular structures in the intestine (Fig. 4). These granules are likely to be fat storage granules, as ACBP-4::GFP expression could not be observed upon RNAi knockdown of sbp-1, the C. elegans homologue of the mammalian lipogenic transcription factor SREBP-1c [39] (results not shown). Furthermore, under the light microscope, the ACBP-4::GFP-labeled granules have the smooth appearance of fat storage granules and not the more-obviously structured appearance of lysosomes. However, we cannot completely rule out the possibility that ACBP$4::$ GFP is also associated with lysosomes. ACBP-6 is uniquely expressed in specific head, body, and tail neurons (Fig. 4). The neuronal expression of pacbp-6::GFP in the mid-body may be the CAN neurons, while the neuron in the head is located dorsally posterior to the posterior bulb of the pharynx and may be the AVG command interneuron.

Of the ACBPs that also contain other domains ACBP-2::GFP is expressed in the intestine and in the hypodermis of adult animals (Fig. 4). In adult animals, ACBP-5 localizes to the pharynx and intestine, and expression is highest in the anterior part of the intestine (Fig. 4).

\section{Loss of ACBP-1 function shortens $C$. elegans lifespan}

To investigate the function of each of the ACBP paralogues, we isolated or obtained strains carrying genomic mutations in each of the individual $a c b p$ genes. We screened a deletion library and isolated one deletion allele of $a c b p-1, s v 62$, and one of $a c b p-3, s v 73$. Sequencing of the $s v 62$ allele revealed that it removes all of exon 1, including the start codon (Fig. 1D). We confirmed that the $s v 62$ allele is likely to eliminate $a c b p-1$ gene activity, since no expression can be detected by qRT-PCR (results not shown). We likewise confirmed by qRTPCR that $s v 73$ removes exons 1 and 2 and is, therefore, likely to be a null-mutant (Fig. 1D) (results not shown).

The deletion allele acbp-2, tm3573, lacks parts of exon2 and exon 3 encoding parts of the gene product containing the enzymatic domain but not the $a c b p$-domain. The $a c b p-4$ mutant allele, $t m 2896$, lacks exon one and approximately half of exon 2 , and is predicted to encode a protein lacking alpha helices 1 and 2 of ACBP-4. The ok1692 deletion in $a c b p-5$ spans exons 3 through 5, thereby leaving the ACBP-domain-encoding exons (exons 1 and 2) intact, while the sequences encoding the ankyrin repeats are deleted. The acbp-6 mutant allele, tm2995, is a $24 \mathrm{bp}$ insertion followed by a 267 bp deletion that removes exon 3, which encodes alpha helix 3 and -4 of ACBP-6.

Disruption of ACBP-1 function was shown to significantly reduce worm lifespan from 14 to 9 days $(p<0.0001)$. The survival curves for all single mutants are shown in Fig. S1, and are representative of three independent experiments. All of the acbp single mutants appeared healthy and displayed no obvious differences in brood size compared to wild-type. 


\section{Disruption of ACBP-1 function alters lipid droplet size and number}

An emerging method for examining $C$. elegans fat stores in a non-invasive manner is the coherent anti-Stokes Raman scattering microscopy technique [31]. This method has recently been used to confirm aberrant lipid storage in response to altered insulin- and TGF- $\beta$ signalling [31], SBP-1 function [31], and synthesis of unsaturated fatty acids [31] in $C$. elegans. CARS analyses revealed profound changes in the morphology and number of the lipid droplets in particular in the $a c b p-1, a c b p-2$, and $a c b p-3$ mutants. The $a c b p-1$ mutant contains approximately $70 \%$ fewer lipid droplets compared to N2 animals, however, the majority of these droplets have a diameter approximately 3.8 times that of the average lipid droplet in wild-type animals (Fig. 5). We also find that $a c b p-2$ mutants contain approximately $40 \%$ fewer lipid droplets. However, the average size of the droplets is not significantly different from that in wild-type. Compared to the lipid droplets in N2 animals, the average diameter of the lipid droplets in the $a c b p-3$ mutants is approximately $30 \%$ smaller, while the droplet number is not significantly different from wild-type. Disruption of ACBP-5 function results in 1.4 times more lipid droplets than in wild-type animals.

In a genome-wide knockdown screen RNAi of $a c b p-1$ was found to decrease Nile Red staining in the worm intestine indicative of reduced fat storage [40]. By enzymatic determination of total extractable triglycerides, we confirmed that functional loss of ACBP-1 results in $25 \%$ less triglycerides. We further found, that disruption of ACBP-2 and ACBP-3 function result in $18 \%$ and $20 \%$ less triglycerides, respectively, compared to wild-type levels (Fig. 6). Surprisingly, despite the fact that the triglyceride level is not different from wildtype levels (Fig. 6), CARS analysis of a quadruple mutant, lacking all the basal ACBPs (acbp-1;acbp-6;acbp-4;acbp-3) demonstrates that the fat stores are dispersed in the cytoplasm of the intestinal cells rather than being assembled in distinct lipid droplet structures. Collectively, these data suggest that acyl-CoA binding proteins are required for lipid droplet morphology and lipid storage function in C. elegans.

CARS imaging and Raman analysis of single lipid droplets have recently shown that the ratio between the Raman-active bands at $1660 \mathrm{~cm}^{-1}$ and $1445 \mathrm{~cm}^{-1}\left(\mathrm{I}_{1660} / \mathrm{I}_{1445}\right)$ can be used as a reliable measure of the degree of lipid-chain unsaturation [31]. We found that loss of ACBP1, ACBP-3, ACBP-4, or ACBP-6 results in 35-40\% reduction in lipid chain unsaturation compared to wild-type, while loss of ACBP-2 function increased lipid chain unsaturation by 1.25 times (Fig. $5 \mathrm{~K}$ ). In contrast to these results, we were unable to detect any changes in either specific fatty acid species or acyl-chain unsaturation by gas chromatography of total lipids (Fig. S2), suggesting that the acyl-chain composition in the triglycerides within the droplets is different from the whole-body acyl-chain composition. It was not possible to determine the degree of lipid chain unsaturation in the quadruple mutant due to the dispersion of the lipids.

\section{Loss of ACBP-2/ECH-4 function affects oxidation of fatty acids in vivo}

Since ACBD1 has previously been shown to mediate intermembrane transport of acyl-CoA esters in vitro and to facilitate their transport to mitochondria for $\beta$-oxidation [41], we were prompted to examine fatty acid oxidation in live C. elegans in response to loss of ACBP function. Fatty acid oxidation has previously been determined in mammalian cells [34] and purified mitochondria [41] by examining the conversion of a tritiated fatty acid to tritiated $\mathrm{H}_{2} \mathrm{O}$. Hence, we incubated live $C$. elegans in an aqueous buffer containing fatty acid complexed to BSA for one hour and determined the amount of ${ }^{3} \mathrm{H}_{2} \mathrm{O}$ generated. Compared to controls without live animals, addition of increasing number of live worms resulted in linear 
increase in the amount of labeled $\mathrm{H}_{2} \mathrm{O}$ formed (data not shown). Addition of $1 \mathrm{mM}$ sodium azide to the assay reduced oxidation of oleic acid to approximately $15 \%$ of untreated samples (Fig. 7). Moreover, killing animals by boiling ablated fatty acid oxidation (Elle, I. C.; Færgeman, N. J.; manuscript in preparation).

By sequence homology, ACBP-2/ECH-4 is predicted to be a $\Delta 3, \Delta 2$-enoyl-CoA hydratase/isomerase (enoyl-CoA hydratase/isomerase), which catalyzes 3-cis to 2-trans and 3-trans to 2-trans isomerizations of enoyl-CoA esters and the 2,5- to 3,5 isomerization of dienoyl-CoA esters. Accordingly, disruption of the enoyl-CoA hydratase/isomerase domain within ACBP-2/ECH-4 resulted in a significant decrease in oxidation of oleic acid, whereas oxidation of palmitic acid increased 2-fold in response to loss of ACBP-2 function (Fig. 7A, B). These observations substantiate the predicted role of ACBP-2/ECH-4 in $\beta$-oxidation of unsaturated fatty acids, but also suggest that $C$. elegans with loss of ACBP-2 function compensate by upregulating degradation of saturated fatty acids. Interestingly, we found by qRT-PCR that several genes encoding enzymes involved in peroxisomal and mitochondrial $\beta$-oxidation were up-regulated in $a c b p-2$ animals (Fig. S3). Moreover, the increase in acylchain unsaturation in the lipid droplets of $a c b p-2$ mutants (Fig. 5L) correlates well with the alterations in oxidation of saturated and unsaturated fatty acids (Fig. 7A, B), respectively, in these animals.

This assay allowed us to examine fatty acid oxidation in response to loss of the other ACBP paralogues. Interestingly, we found that loss of function in acbp-1 or -3 results in small but significant increases in the oxidation of oleic acid, whereas functional disruption of the other ACBPs did not affect degradation of oleic acid. Interestingly, we found that the quadruple mutant displays a 2.5-fold increase in oxidation of oleic acid compared to wild-type (Fig. $7 \mathrm{~A})$.

\section{Starvation induces mobilization of triglyceride stores and oxidation of fatty acids}

Like mammals, C. elegans is able to mobilize triglyceride stores and to up-regulate the fatty acid oxidation capacity in response to starvation [42]. By CARS microscopy we find six and 12 hours of starvation caused a dramatic decrease in the number and size of the lipid droplets (Fig. 8A). To corroborate these findings, we determined oxidation of oleic acid in response to starvation and found that oxidation increases up to 5-fold after six hours of starvation (Fig. $8 \mathrm{~B})$. The enlarged lipid droplets in the acbp-1 mutant led us to examine its ability to mobilize and degrade its lipid stores. We found that $a c b p-1$ animals can mobilize their lipid stores (Fig. 8A) and up-regulate their ability to oxidize fatty acids to a similar level as wild-type animals (Fig. 8B).

\section{ACBP-2 is transcriptionally regulated by NHR-49}

The expression of genes involved in lipid metabolism in C. elegans is co-ordinately controlled by a number of transcription factors including the nuclear hormone receptor 49 (NHR-49), which is an HNF-4 $\alpha$ homologue and has a function analogous to that of PPAR $\alpha$ in mammals [42]. Expression of lipid-related genes is also regulated by a membrane-tethered transcription factor SBP-1, whose function is analogous to that of mammalian SREBP-1c [39]. NHR-49 has previously been shown to play an important role as a transcriptional regulator of $\beta$-oxidation genes under fed and starvation conditions [42], and SBP-1 has been shown to be required for efficient expression of genes involved in fatty acid synthesis [39]. The fact that the expression of ACBD1 has been shown to be regulated by both PPAR $\alpha$ and by SREBP-1c in rodent hepatocytes [43] prompted us to examine the role of NHR-49 and SBP-1 in the regulation of $a c b p$ expression in C. elegans. We confirmed that, as previously 
reported [42], the expression of ech-8 and gei-7 (encoding a peroxisomal Hydroxyacyl-CoA dehydrogenase/enoyl-CoA hydratase and malate synthase, respectively) is reduced in worms lacking $n h r-49$ activity (Fig. S4A).

Consistent with its predicted function in mitochondrial $\beta$-oxidation, we found that $a c b p$ 2/ech-4 expression is reduced to approximately $50 \%$ of the wild-type level in $n h r-49$ ( $n r 2041)(F i g$. S4A). In keeping with this, knockdown of $n h r-49$ expression by RNAi reduced the level of ACBP-2::GFP fluorescence (Fig. S4C and S4D). None of the other acbp genes were found to be dysregulated in $n h r-49(n r 2041)$ animals. While knockdown of $s b p-1$ expression in $\mathrm{N} 2$ animals by RNAi resulted in significant down-regulation of the pod-2 (encoding acetyl-CoA carboxylase) and the fat- 6 gene (encoding a $\Delta 9$-desaturase) as previously observed $(68,70)$, we did not observe any change in the expression levels of the acbp genes (Fig. S4B).

\section{Discussion}

In the present study we provide evidence that the $C$. elegans paralogues ACBP-1 to ACBP-6 function as acyl-CoA binding proteins in the worm: They complement a lack of Acb1 in Saccharomyces cerevisiae, and they are expressed in vivo in $C$. elegans. Based on mRNA expression level ACBP-1 is the most abundant acyl-CoA binding protein at the L4 larval stage in C. elegans. Loss of the ACBP-1 function results in fewer but enlarged lipid droplets and in decreased levels of total triacylglycerols, suggesting that ACBP-1 is involved in storage of triglycerides and in maintenance of normal lipid droplet size. A function in lipid biosynthesis is consistent with recent studies showing that knockout of ACBD1 results in decreased lipid synthesis in both rodent and in human cell lines [25, 28]. Conversely, overexpression of ACBD1 in rodents [27] and in McA-RH7777 rat hepatoma cells [26] results in increased synthesis of triacylglycerols. Similarly, knockdown of ACBP in Bombyx mori results in decreased levels of triacylglycerols [44]. Conditional depletion of Acb1 in Saccharomyces cerevisiae has also been found to impair synthesis of phospholipids, ceramides, and sphingolipids [22-23], which further supports a function in lipid synthesis.

Despite the fact that we find ACBP-1 to be required for normal triglyceride storage, lipid droplet size, and fatty acid oxidation, expression of $a c b p-1$ is not transcriptionally regulated by SBP-1 or NHR-49, which have previously been shown to regulate the expression of genes involved in biosynthesis and degradation of fatty acids and lipids, respectively [39, 42]. This observation could imply that ACBP-1 generally mediates the intracellular flux of activated fatty acids. This notion is supported by the fact that over-expression of ACBD1 in McARH7777 rat hepatoma cells not only increased synthesis of triacylglycerols but also decreased $\beta$-oxidation of exogenous fatty acids [26], and that recombinant bovine ACBD1 is able to mediate intermembrane transport of acyl-CoA to both microsomal glycerolipid synthesis and to mitochondrial $\beta$-oxidation [41]. Our studies also show that impaired ACBP-1 function results in significantly enlarged lipid droplets in the intestine. Vaccenic acid (C18:1n7) has recently been found to regulate lipid droplet size in C. elegans [45], however, we do not detect any change in vaccenic acid levels either in $a c b p-1$ animals or any of the other $a c b p$ mutants. Alternatively, altered acyl chain length may affect packing of lipids and consequently the morphology and size of lipid droplets. Disruption of Acb1 function in $S$. cerevisiae decreases the average length of the acyl chains in phospholipids [38], however, to what extent the length of the acyl chains in triglycerides affects the size and morphology of lipid droplets is not known.

The present study also shows that ACBP-2/ECH-4 is required for $\beta$-oxidation of unsaturated fatty acids and is transcriptionally regulated by the nuclear hormone receptor NHR-49, which 
is known to regulate the expression of genes encoding $\beta$-oxidation enzymes [42]. Consistently, ACBP-2/ECH-4 is expressed at relatively high levels in both the intestine and the hypodermis, two metabolically active tissues, which are the major fat storing tissues in $C$. elegans. Enoyl-CoA hydratases/isomerases have also been shown to be required for degradation of unsaturated fatty acids in Saccharomyces cerevisiae [46], Arabidopsis thaliana [47], and in rodents [48]. Surprisingly, we find that oxidation of palmitic acid is increased 2-fold in acbp-2 mutants, which implies that $\beta$-oxidation enzymes involved in degradation of saturated fatty acids are up-regulated in $a c b p-2$ mutants conceivably to compensate for decreased oxidation of unsaturated fatty acids. This hypothesis is supported by the fact that several genes encoding enzymes predicted to be involved in fatty acid oxidation are up-regulated in $a c b p-2$ mutants (Fig. S3). Interestingly, the impaired degradation of unsaturated fatty acids and increased degradation of saturated fatty acids in $a c b p-2$ animals is inversely reflected in the acyl-chain composition of the triglycerides in lipid droplets as the degree of unsaturation of acyl-chains increases in response to loss of ACBP-2/ECH-4 function as examined by CARS microscopy. This suggests that storage of acyl-chains in lipid droplets and fatty acid degradation also are closely linked in C. elegans. Accordingly, no lipid droplets are visible in wild-type C. elegans after six and 12 hours of starvation, concurrent with an approximately 3-fold up-regulation of oleic acid oxidation.

The subtle phenotypes induced by functional loss of individual acyl-CoA binding proteins in C. elegans suggest that these proteins can functionally replace each other or that other functionally redundant proteins can compensate for loss of these. These redundancies may in fact be mediated by other lipid binding proteins than acyl-CoA binding proteins, since an $a c b p-1 ; a c b p-6 ; a c b p-4 ; a c b p-3$ quadruple mutant lacking all of the short ACBP forms appears healthy and only slightly developmentally delayed. Moreover, disruption of the only ACBPencoding gene in Saccharomyces cerevisiae, results in unstable cells, which undergo adaptational changes that enable them to grow like wild-type cells [22], arguing that other, yet unknown proteins, can replace Acbl function in response to long-term loss of ACBP in Saccharomyces cerevisiae. However, the fact that the quadruple mutant contains no visible lipid droplets regardless of normal triacylglycerol levels suggests that the presence of at least one basal ACBP is required for lipid droplet formation in C. elegans.

Although ACBP paralogues may functionally replace each other under certain circumstances, it is very likely that each of the paralogues has developed to serve a specific function. Duplication of genes is considered to be the most important evolutionary process for generating novel protein functions. For instance, it is recognized that changing the subcellular localization or tissue-specific expression of a protein can alter its function, but also that subcellular re-localization of a protein represents an important mechanism for retention of gene duplicates [49]. Examination of the ratios of non-synonymous/synonymous substitution rates $\left(\mathrm{K}_{\mathrm{a}} / \mathrm{K}_{\mathrm{s}}\right)$ demonstrates that the $C$. elegans acbp genes have been subjected to a strong purifying selection with $\mathrm{K}_{\mathrm{a}} / \mathrm{K}_{\mathrm{s}}$-ratios ranging from $0.22-0.80$, indicating that these genes have been exposed to pressures to conserve protein sequence and function. The differences in their spatial expression may therefore indicate that the function of the ACBP paralogues have diverged via tissue-specific expression. It is therefore interesting to speculate what the function of the various acyl-CoA binding proteins could be. One possibility is that some of the ACBPs function in specialized processes, which utilize or are regulated by acyl-CoA esters. For example, we have previously shown that the membrane-associated acyl-CoA binding protein, MAA-1, may mediate the regulatory function of acyl-CoA in vesicular trafficking [30]. Interestingly, homologues of each of the C. elegans acyl-CoA binding proteins have also been identified in other invertebrates such as fruit flies, in mammals, and 
Arabidopsis thaliana (table S1). Recent studies in A. thaliana clearly demonstrate that different ACBP paralogues perform individual and specialized functions (reviewed in [50]). Based on its sequence homology to ACBD1 and its size, ACBP6 is considered the basal 10 $\mathrm{kDa}$ paralogue in A. thaliana (Table S1). Accordingly, it is also localized to the cytosol and has been shown to be involved in phospholipid metabolism and in cold-tolerance. ACBP1 from $A$. thaliana is a $37.5 \mathrm{kDa}$ protein that contains ankyrin repeats, similar to ACBP-5 in $C$. elegans, and has been shown to associate with the plasma membrane and regulate coldtolerance and lead-induced stress. ACBP2, which is homologous to ACBP-4 and ACBP-6 from $C$. elegans, is membrane-associated and contains ankyrin repeats through which it interacts with ethylene-responsive element binding protein AtEBP, a transcription factor involved in plant pathogen defence. Both ACBP1 and -2 have been proposed to function in maintaining an acyl-CoA pool at the plasma membrane and participate in membrane biogenesis in $A$. thaliana. ACBP3 is an extracellularly targeted ACBP implicated in leaf senescence and has been shown to disrupt autophagosome formation by enhancing the degradation of the autophagosomal marker protein ATG8. ACBP4 and -5 contain kelch motifs, are localized to the cytosol, and have been proposed to transport acyl-CoAs from the chloroplasts to the endoplasmic reticulum for fatty acid modification.

In conclusion, the present work represents the first study to systematically address the function of multiple acyl-CoA binding proteins in a multicellular animal. We have shown that loss of ACBP-1 function results in diminished triglyceride accumulation, altered lipid droplet morphology, and increased fatty acid oxidation. Hence, we hypothesize that ACBP-1 mediates the intracellular flux of fatty acyl-CoA esters to acyl-CoA utilizing processes. We also show that the enoyl-CoA hydratase domain of ACBP-2 is required for degradation of unsaturated fatty acids. Future investigations using mutants carrying other or more than one dysfunctional ACBP allele are needed to establish possible redundant roles of each of the ACBP paralogues and to identify novel genes that can compensate for loss of ACBP function. The present study has addressed the phenotypes associated with loss of one of the ACBP paralogues in fed worms, however, we acknowledge that the phenotypes with may be more pronounced under more stressful conditions such as starvation or dietary restriction. The genetic tractability of $C$. elegans and the mutant strains we have obtained so far provide an excellent framework for such studies.

Acknowledgements: We gratefully appreciate Agneta Rönnlund for generating transgenic animals and Assistant Professor Kaveh Ashrafi for valuable discussions. We thank Dr. Roger Pocock for assistance in identifying ACBP-6-expressing neurons. We apologize in advance to authors whose work we have not cited due to space limitations.

Funding: The present work was supported by funds from The Danish Research Councils (grant number 23363) and The Novo-Nordisk Foundation (grant number 13514).

Financial disclosure: There are no financial conflicts concerning this work.

\section{References}

1 van Aalten, D. M., DiRusso, C. C. and Knudsen, J. (2001) The structural basis of acyl coenzyme A-dependent regulation of the transcription factor FadR. Embo J. 20, 20412050 
2 White, U. A. and Stephens, J. M. (2010) Transcriptional factors that promote formation of white adipose tissue. Mol Cell Endocrinol. 318, 10-14

3 Elle, I. C., Olsen, L. C., Pultz, D., Rodkaer, S. V. and Faergeman, N. J. (2010) Something worth dyeing for: molecular tools for the dissection of lipid metabolism in Caenorhabditis elegans. FEBS Lett. 584, 2183-2193

$4 \quad$ Kuhnlein, R. P. (2010) Drosophila as a lipotoxicity model organism--more than a promise? Biochim Biophys Acta. 1801, 215-221

5 Li, L. O., Klett, E. L. and Coleman, R. A. (2010) Acyl-CoA synthesis, lipid metabolism and lipotoxicity. Biochim Biophys Acta. 1801, 246-251

6 Black, P. N., Zhang, Q., Weimar, J. D. and DiRusso, C. C. (1997) Mutational analysis of a fatty acyl-coenzyme A synthetase signature motif identifies seven amino acid residues that modulate fatty acid substrate specificity. J Biol Chem. 272, 4896-4903

7 Faergeman, N. J., Black, P. N., Zhao, X. D., Knudsen, J. and DiRusso, C. C. (2001) The Acyl-CoA synthetases encoded within FAA1 and FAA4 in Saccharomyces cerevisiae function as components of the fatty acid transport system linking import, activation, and intracellular Utilization. J Biol Chem. 276, 37051-37059

8 Zhang, Y., Chen, D. and Wang, Z. (2009) Analyses of mental dysfunction-related ACS14 in Drosophila reveal its requirement for Dpp/BMP production and visual wiring in the brain. Human molecular genetics. 18, 3894-3905

9 Mullaney, B. C., Blind, R. D., Lemieux, G. A., Perez, C. L., Elle, I. C., Faergeman, N. J., Van Gilst, M. R., Ingraham, H. A. and Ashrafi, K. (2010) Regulation of C. elegans fat uptake and storage by acyl-CoA synthase-3 is dependent on NR5A family nuclear hormone receptor nhr-25. Cell Metab. 12, 398-410

10 Kage-Nakadai, E., Kobuna, H., Kimura, M., Gengyo-Ando, K., Inoue, T., Arai, H. and Mitani, S. (2010) Two very long chain fatty acid acyl-CoA synthetase genes, acs-20 and acs-22, have roles in the cuticle surface barrier in Caenorhabditis elegans. PLoS One. 5, e8857

11 Ellis, J. M., Frahm, J. L., Li, L. O. and Coleman, R. A. (2010) Acyl-coenzyme A synthetases in metabolic control. Current opinion in lipidology. 21, 212-217

12 Faergeman, N. J. and Knudsen, J. (1997) Role of long-chain fatty acyl-CoA esters in the regulation of metabolism and in cell signalling. Biochem J. 323 ( Pt 1), 1-12

13 Mogensen, I. B., Schulenberg, H., Hansen, H. O., Spener, F. and Knudsen, J. (1987) A novel acyl-CoA-binding protein from bovine liver. Effect on fatty acid synthesis. Biochem J. 241, 189-192

14 Hansen, J. S., Faergeman, N. J., Kragelund, B. B. and Knudsen, J. (2008) AcylCoA-binding protein (ACBP) localizes to the endoplasmic reticulum and Golgi in a liganddependent manner in mammalian cells. Biochem J. 410, 463-472

15 Faergeman, N. J., Wadum, M., Feddersen, S., Burton, M., Kragelund, B. B. and Knudsen, J. (2007) Acyl-CoA binding proteins; structural and functional conservation over 2000 MYA. Mol Cell Biochem. 299, 55-65

16 Kragelund, B. B., Andersen, K. V., Madsen, J. C., Knudsen, J. and Poulsen, F. M. (1993) Three-dimensional structure of the complex between acyl-coenzyme A binding protein and palmitoyl-coenzyme A. J Mol Biol. 230, 1260-1277

17 Eaergeman, N. J., Sigurskjold, B. W., Kragelund, B. B., Andersen, K. V. and Knudsen, J. (1996) Thermodynamics of ligand binding to acyl-coenzyme A binding protein studied by titration calorimetry. Biochemistry. 35, 14118-14126

18 Mandrup, S., Hummel, R., Ravn, S., Jensen, G., Andreasen, P. H., Gregersen, N., Knudsen, J. and Kristiansen, K. (1992) Acyl-CoA-binding protein/diazepam-binding 
inhibitor gene and pseudogenes. A typical housekeeping gene family. J Mol Biol. 228, 10111022

19 Landrock, D., Atshaves, B. P., McIntosh, A. L., Landrock, K. K., Schroeder, F. and Kier, A. B. (2010) Acyl-CoA binding protein gene ablation induces pre-implantation embryonic lethality in mice. Lipids. 45, 567-580

20 Faergeman, N. J. and Knudsen, J. (2002) Acyl-CoA binding protein is an essential protein in mammalian cell lines. Biochem J. 368, 679-682

21 Milne, K. G., Guther, M. L. and Ferguson, M. A. (2001) Acyl-CoA binding protein is essential in bloodstream form Trypanosoma brucei. Mol Biochem Parasitol. 112, 301-304

22 Gaigg, B., Neergaard, T. B., Schneiter, R., Hansen, J. K., Faergeman, N. J., Jensen, N. A., Andersen, J. R., Friis, J., Sandhoff, R., Schroder, H. D. and Knudsen, J. (2001) Depletion of acyl-coenzyme A-binding protein affects sphingolipid synthesis and causes vesicle accumulation and membrane defects in Saccharomyces cerevisiae. Mol Biol Cell. 12, $1147-1160$

23 Faergeman, N. J., Feddersen, S., Christiansen, J. K., Larsen, M. K., Schneiter, R., Ungermann, C., Mutenda, K., Roepstorff, P. and Knudsen, J. (2004) Acyl-CoA-binding protein, Acblp, is required for normal vacuole function and ceramide synthesis in Saccharomyces cerevisiae. Biochem J. 380, 907-918

24 Lee, L., Debono, C. A., Campagna, D. R., Young, D. C., Moody, D. B. and Fleming, M. D. (2006) Loss of the Acyl-CoA Binding Protein (Acbp) Results in Fatty Acid Metabolism Abnormalities in Mouse Hair and Skin. J Invest Dermatol

25 Mandrup, S., Sorensen, R. V., Helledie, T., Nohr, J., Baldursson, T., Gram, C., Knudsen, J. and Kristiansen, K. (1998) Inhibition of 3T3-L1 adipocyte differentiation by expression of acyl-CoA-binding protein antisense RNA. J Biol Chem. 273, 23897-23903

26 Yang, Y., Pritchard, P. H., Bhuiyan, J., Seccombe, D. W. and Moghadasian, M. H. (2001) Overexpression of acyl-coA binding protein and its effects on the flux of free fatty acids in McA-RH 7777 cells. Lipids. 36, 595-600

27 Huang, H., Atshaves, B. P., Frolov, A., Kier, A. B. and Schroeder, F. (2005) Acylcoenzyme A binding protein expression alters liver fatty acyl-coenzyme A metabolism. Biochemistry. 44, 10282-10297

28 Vock, C., Biedasek, K., Boomgaarden, I., Heins, A., Nitz, I. and Doring, F. (2010) ACBP knockdown leads to down-regulation of genes encoding rate-limiting enzymes in cholesterol and fatty acid metabolism. Cell Physiol Biochem. 25, 675-686

29 Brenner, S. (1974) The genetics of Caenorhabditis elegans. Genetics. 77, 71-94

30 Larsen, M. K., Tuck, S., Faergeman, N. J. and Knudsen, J. (2006) MAA-1, a novel acyl-CoA-binding protein involved in endosomal vesicle transport in Caenorhabditis elegans. Mol Biol Cell. 17, 4318-4329

31 Le, T. T., Duren, H. M., Slipchenko, M. N., Hu, C. D. and Cheng, J. X. (2010) Label-free quantitative analysis of lipid metabolism in living Caenorhabditis elegans. J Lipid Res. 51, 672-677

32 Bligh, E. G. and Dyer, W. J. (1959) A rapid method of total lipid extraction and purification. Can J Biochem Physiol. 37, 911-917

33 Rodriguez-Sureda, V. and Peinado-Onsurbe, J. (2005) A procedure for measuring triacylglyceride and cholesterol content using a small amount of tissue. Anal Biochem. 343, 277-282

34 Moon, A. and Rhead, W. J. (1987) Complementation analysis of fatty acid oxidation disorders. J Clin Invest. 79, 59-64 
35 Kragelund, B. B., Poulsen, K., Andersen, K. V., Baldursson, T., Kroll, J. B., Neergard, T. B., Jepsen, J., Roepstorff, P., Kristiansen, K., Poulsen, F. M. and Knudsen, J. (1999) Conserved residues and their role in the structure, function, and stability of acylcoenzyme A binding protein. Biochemistry. 38, 2386-2394

36 Hiltunen, J. K. and Qin, Y. (2000) beta-oxidation - strategies for the metabolism of a wide variety of acyl-CoA esters. Biochim Biophys Acta. 1484, 117-128

37 Li, H. Y. and Chye, M. L. (2004) Arabidopsis Acyl-CoA-binding protein ACBP2 interacts with an ethylene-responsive element-binding protein, AtEBP, via its ankyrin repeats. Plant Mol Biol. 54, 233-243

38 Feddersen, S., Neergaard, T. B., Knudsen, J. and Faergeman, N. J. (2007) Transcriptional regulation of phospholipid biosynthesis is linked to fatty acid metabolism by an acyl-CoA-binding-protein-dependent mechanism in Saccharomyces cerevisiae. Biochem J. 407, 219-230

39 McKay, R. M., McKay, J. P., Avery, L. and Graff, J. M. (2003) C elegans: a model for exploring the genetics of fat storage. Dev Cell. 4, 131-142

40 Ashrafi, K., Chang, F. Y., Watts, J. L., Fraser, A. G., Kamath, R. S., Ahringer, J. and Ruvkun, G. (2003) Genome-wide RNAi analysis of Caenorhabditis elegans fat regulatory genes. Nature. 421, 268-272

41 Rasmussen, J. T., Faergeman, N. J., Kristiansen, K. and Knudsen, J. (1994) AcylCoA-binding protein (ACBP) can mediate intermembrane acyl-CoA transport and donate acyl-CoA for beta-oxidation and glycerolipid synthesis. Biochem J. 299 ( Pt 1), 165-170

42 Van Gilst, M. R., Hadjivassiliou, H. and Yamamoto, K. R. (2005) A Caenorhabditis elegans nutrient response system partially dependent on nuclear receptor NHR-49. Proc Natl Acad Sci U S A. 102, 13496-13501

43 Sandberg, M. B., Bloksgaard, M., Duran-Sandoval, D., Duval, C., Staels, B. and Mandrup, S. (2005) The gene encoding acyl-CoA-binding protein is subject to metabolic regulation by both sterol regulatory element-binding protein and peroxisome proliferatoractivated receptor alpha in hepatocytes. J Biol Chem. 280, 5258-5266

44 Ohnishi, A., Hull, J. J. and Matsumoto, S. (2006) Targeted disruption of genes in the Bombyx mori sex pheromone biosynthetic pathway. Proc Natl Acad Sci U S A. 103, 4398-4403

45 Zhang, S. O., Box, A. C., Xu, N., Le Men, J., Yu, J., Guo, F., Trimble, R. and Mak, H. Y. (2010) Genetic and dietary regulation of lipid droplet expansion in Caenorhabditis elegans. Proc Natl Acad Sci U S A

46 Gurvitz, A., Mursula, A. M., Firzinger, A., Hamilton, B., Kilpelainen, S. H., Hartig, A., Ruis, H., Hiltunen, J. K. and Rottensteiner, H. (1998) Peroxisomal Delta3-cis-Delta2trans-enoyl-CoA isomerase encoded by ECI1 is required for growth of the yeast Saccharomyces cerevisiae on unsaturated fatty acids. J Biol Chem. 273, 31366-31374

47 Goepfert, S., Vidoudez, C., Rezzonico, E., Hiltunen, J. K. and Poirier, Y. (2005) Molecular identification and characterization of the Arabidopsis delta(3,5), delta(2,4)-dienoylcoenzyme $\mathrm{A}$ isomerase, a peroxisomal enzyme participating in the beta-oxidation cycle of unsaturated fatty acids. Plant physiology. 138, 1947-1956

48 Qi, C., Zhu, Y., Pan, J., Usuda, N., Maeda, N., Yeldandi, A. V., Rao, M. S., Hashimoto, T. and Reddy, J. K. (1999) Absence of spontaneous peroxisome proliferation in enoyl-CoA Hydratase/L-3-hydroxyacyl-CoA dehydrogenase-deficient mouse liver. Further support for the role of fatty acyl CoA oxidase in PPARalpha ligand metabolism. J Biol Chem. 274, 15775-15780 
49 Byun-McKay, S. A. and Geeta, R. (2007) Protein subcellular relocalization: a new perspective on the origin of novel genes. Trends Ecol Evol. 22, 338-344

50 Xiao, S. and Chye, M. L. (2009) An Arabidopsis family of six acyl-CoA-binding proteins has three cytosolic members. Plant Physiol Biochem. 47, 479-484

\section{Figure Legends}

\section{Figure 1}

acbp-1 - 6 encode acyl-CoA binding domain proteins in C. elegans. A. Comparison of the ACBP paralogues in C. elegans. The number of amino acids present in each protein is indicated below the protein name. The ACBP domain is coloured blue, the enoyl-CoA hydratase/isomerase domain in ACBP-2 is grey, the ankyrin repeats in ACBP-5 are yellow, and the coiled-coil domain and the transmembrane domain in MAA-1 are green and pink, respectively. B. Phylogram showing the evolutionary relationship between the $C$. elegans ACBPs, murine liver ACBD1, and the Saccharomyces cerevisiae acyl-CoA binding protein Acb1. The scale bar corresponds to 0.1 substitutions per residue. C. ClustalX alignment of $C$. elegans ACBP-1 to ACBP-6 proteins with murine liver ACBD1 and the Saccharomyces cerevisiae acyl-CoA binding protein Acb1. Single-letter abbreviations for amino acid residues are used. Identical and similar amino acids are identified by black and grey shading, respectively. The alpha helices 1 to 4 are indicated by black lines. D. Genomic organization and deletions of the acbp genes. acbp-1 (C44E4.6; GI: 133902751) is located on chromosome I, acbp-2 (R06F6.9; GI: 212645496) and acbp-6 (Y17G7B.1; GI: 193205102) on chromosome II, acbp-3 (F47B10.7; GI: 86564913) on chromosome X, and acbp-4 (F56C9.5; GI: 17553665) and $a c b p-5$ (T12D8.3; GI: 193210444) on chromosome III. The coding regions are boxed and non-coding regions are shown as lines. The red lines below each gene indicate deletions in the mutants used. The number above each coding region indicates the first amino acid in the particular coding region.

\section{Figure 2}

Ectopic expression of $C$. elegans ACBP paralogues complements Acb1 function in Saccharomyces cerevisiae. A. Wild-type cells transformed with empty vector, Acb1-depleted cells (acb1 $\triangle)$ ectopically expressing Acb1 $(A C B 1)$, or Acb1 unable to bind long-chain acyl$\mathrm{CoA}\left(A C B 1^{\mathrm{Y} 28 \mathrm{~A}, \mathrm{~K} 32 \mathrm{~A}}\right)$ were cultured in minimal glucose-supplemented media and their growth followed over time. B. Wild-type cells transformed with empty vector, Acb1-depleted cells (acb1 $\triangle$ ) ectopically expressing Acb1 ( $A C B 1)$, or one of the acbp-genes from C. elegans were cultured in minimal glucose-supplemented media and their growth followed over time.

\section{Figure 3}

Temporal expression of ACBP paralogues in $C$. elegans. Total RNA was harvested from $\mathrm{N} 2$ worms at the L1 and L4 stage, respectively. ACBP mRNA was quantified using qRTPCR, and values were normalized to $t b p-1$ mRNA and displayed in arbitrary units (a. u.).

\section{Figure 4}

Spatial expression of ACBP isoforms in transgenic $C$. elegans animals. Transgenic lines expressing translational GFP fusions with ACBP-1 (Pacbp-1::ACBP-1::GFP), ACBP-2 (Pacbp-2::ACBP-2::GFP), ACBP-3 (Pacbp-3::ACBP-3::GFP), ACBP-4 (Pacbp-4::ACBP$4:: \mathrm{GFP}$ ), or ACBP-5 (Pacbp-5::ACBP-5::GFP) were constructed and GFP expression in 
L4/adult animals was analyzed by confocal scanning fluorescence microscopy. A transgenic line expressing GFP under the control of the $a c b p-6$ promoter (Pacbp-6::GFP) was obtained from The Caenorhabditis Genetics Center and its expression analyzed in adult animals by confocal scanning fluorescence microscopy. The localization of ACBP-4::GFP to granular structures in the intestine of N2 animals has been enlarged in the middle panel. Scale bar is $0.1 \mathrm{~mm}$. Coloured arrows heads indicate specific tissues/organelles: Light blue: Intestine; red: Hypodermis; yellow: Muscle; dark blue: Intestinal granules; orange: Neurons.

\section{Figure 5}

Imaging and analysis of lipid droplets in acbp mutants by Coherent Anti-Stokes Raman Scattering (CARS) microscopy. A. CARS imaging of lipid (yellow) and TPEF imaging of autofluorescent lipid species (blue) of L4 N2 wild-type and the $a c b p-1, a c b p-2, a c b p-3, a c b p$ 4, acbp-5, acbp-6, and $a c b p-1 ; a c b p-6 ; a c b p-4 ; a c b p-3$ mutants. Images are presented as 3D projections of 25 frames taken along the vertical axis at $1 \mu \mathrm{m}$ interval. Scale bar is $25 \mu \mathrm{m}$. $\mathrm{H}$. The size of each lipid droplet in one representative animal (out of nine analyzed) was determined and plotted as a function of the number of lipid droplets. 1. The diameter of lipid droplets in nine different wild-type or $a c b p$ mutant animals was measured. Average $\pm \mathrm{SEM}$ is shown. J. The total number of lipid droplets was determined in nine wild-type or acbp mutant animals. Average \pm SEM is shown. K. Quantitative analyses of acyl chain unsaturation of lipid droplets in wild-type and $a c b p$ mutants. Error bars represent distribution across lipid droplets measured in nine L4 wild-type or mutant $C$. elegans.

\section{Figure 6}

ACBPs are required for normal triglyceride storage in $C$. elegans. Total lipids were extracted from L4 wild-type or $a c b p$ mutants, and triglyceride levels were determined enzymatically, normalized to protein levels, and expressed relative to wild-type levels. The daf-2(e1370) mutant was included as a high-fat control. Average \pm SEM of at least five independent experiments is shown. Asterisks indicate statistical significance $(*: p<0.05 ; * *$ : $\mathrm{p}<0.01 ; * * *: \mathrm{p}<0.001)$.

\section{Figure 7}

ACBP-2 is required for degradation of oleic acid in $C$. elegans. A. Wild-type and $a c b p$ mutant animals (L4) were incubated with tritiated oleic acid complexed to BSA for one hour and the amount of tritiated water generated by oxidation was determined, normalized to protein levels, and expressed relative to wild-type levels (see experimental section for details). B. Wild-type and $a c b p-2$ mutant animals were incubated in $20 \mu \mathrm{M}$ palmitate (C16:0) or $20 \mu \mathrm{M}$ oleic acid (C18:1) as described above, and the amount of tritiated water generated was determined. Average \pm SEM of at least six independent experiments is shown. Asterisks indicate statistical significance $(*: \mathrm{p}<0.05 ; * *: \mathrm{p}<0.01 ; * * *: \mathrm{p}<0.001)$.

\section{Figure 8}

Lipid stores are depleted, and fatty acid oxidation increases in response to starvation independently of ACBP-1. A-G. CARS imaging of lipid (yellow) and TPEF imaging of autofluorescent lipid species (blue) of L4 N2 wild-type (A-C) and the $a c b p-1$ mutant (D-F) at time 0 (fed) (A, D), and after six (B, E) and $12(\mathrm{C}, \mathrm{F})$ hours of starvation. G. Oxidation of oleic acid was determined in either fed or six hours starved wild-type or acbp-1 mutants as described in the experimental section. Average \pm SEM of at least three independent 
B Biochemical Journal Immediate Publication. Published on 04 May 2011 as manuscript BJ20102099

experiments is shown. Asterisks indicate statistical significance $(*: \mathrm{p}<0.05 ; * *: \mathrm{p}<0.01 ; * * *$ : $\mathrm{p}<0.001)$. 
Biochemical Journal Immediate Publication. Published on 04 May 2011 as manuscript BJ20102099

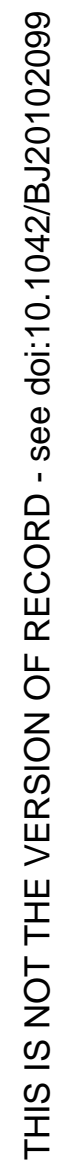

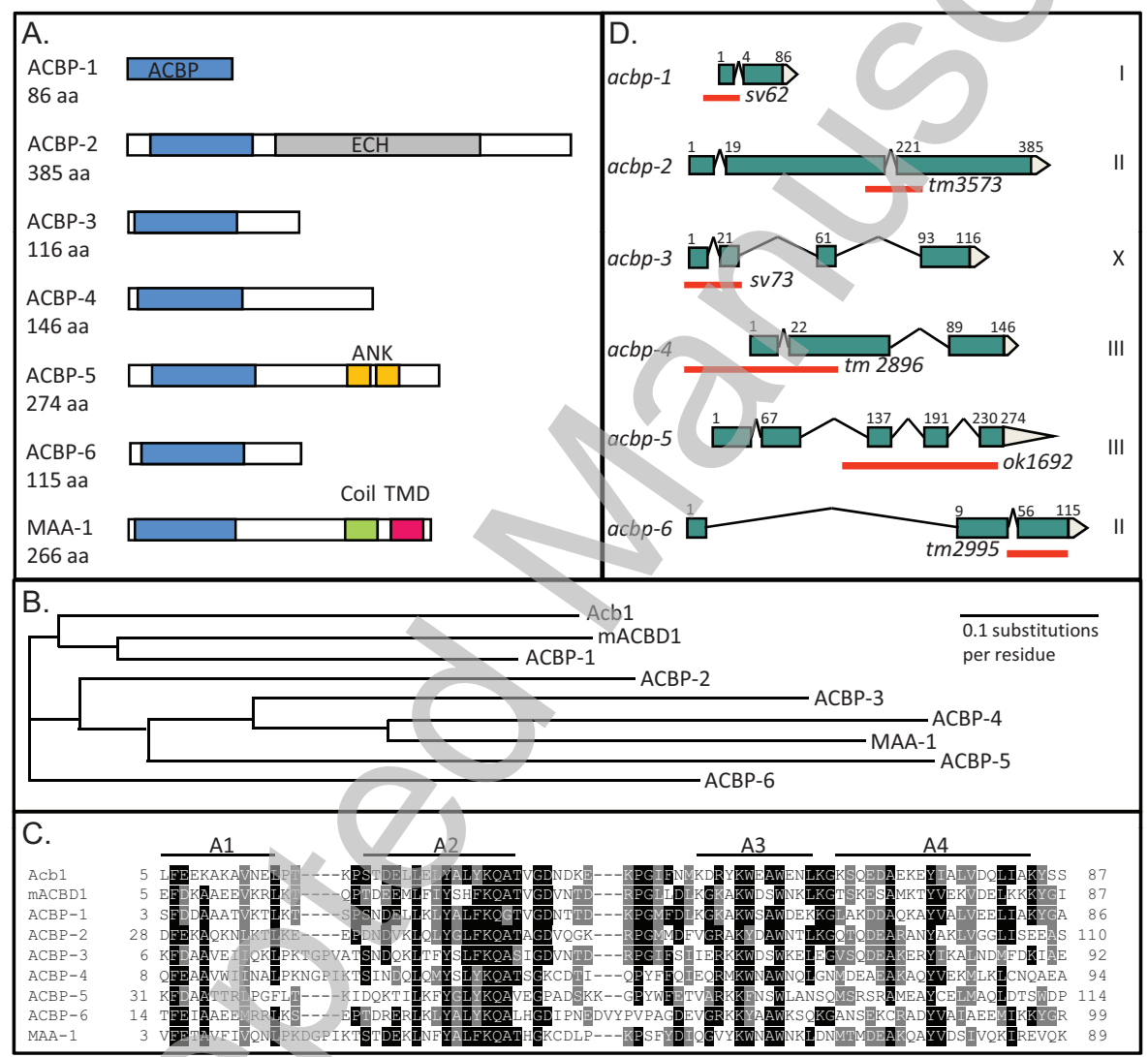

Licenced copy. Copying is not permitted, except with prior permission and as allowed by law. (C) 2011 The Authors Journal compilation (c) 2011 Portland Press Limited 
Biochemical Journal Immediate Publication. Published on 04 May 2011 as manuscript BJ20102099

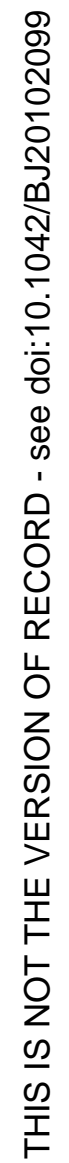

A.

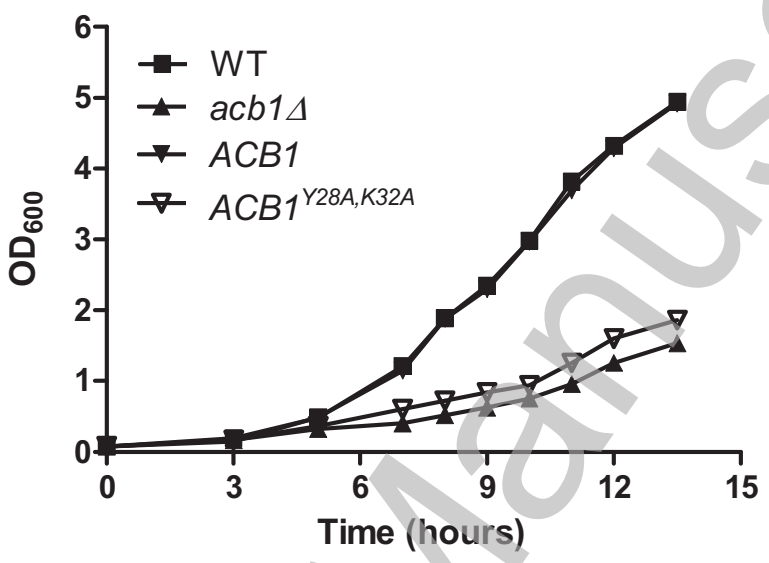

B.

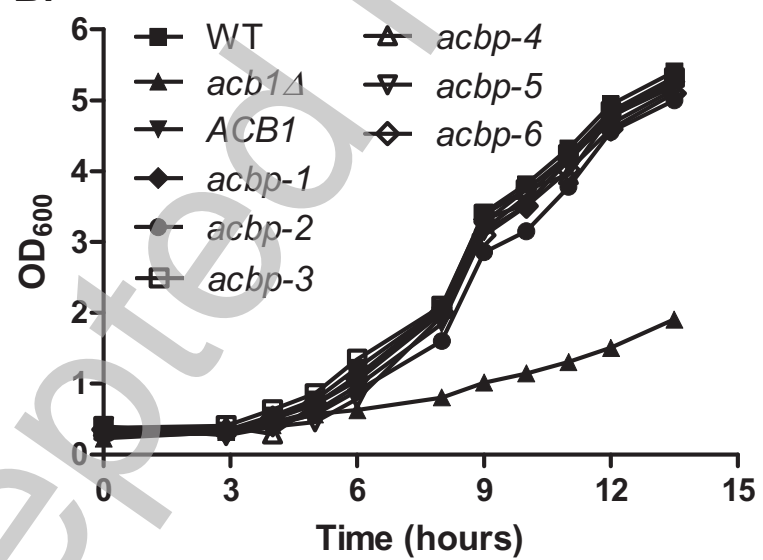

Licenced copy. Copying is not permitted, except with prior permission and as allowed by law. (c) 2011 The Authors Journal compilation (c) 2011 Portland Press Limited 
B Biochemical Journal Immediate Publication. Published on 04 May 2011 as manuscript BJ20102099

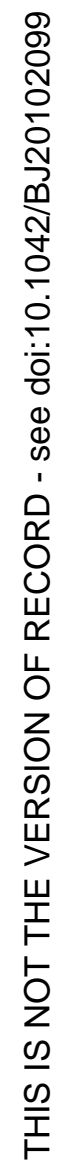

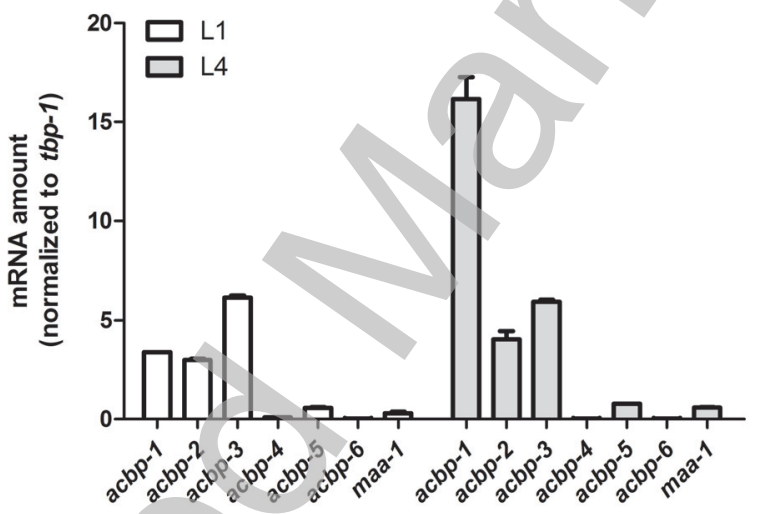



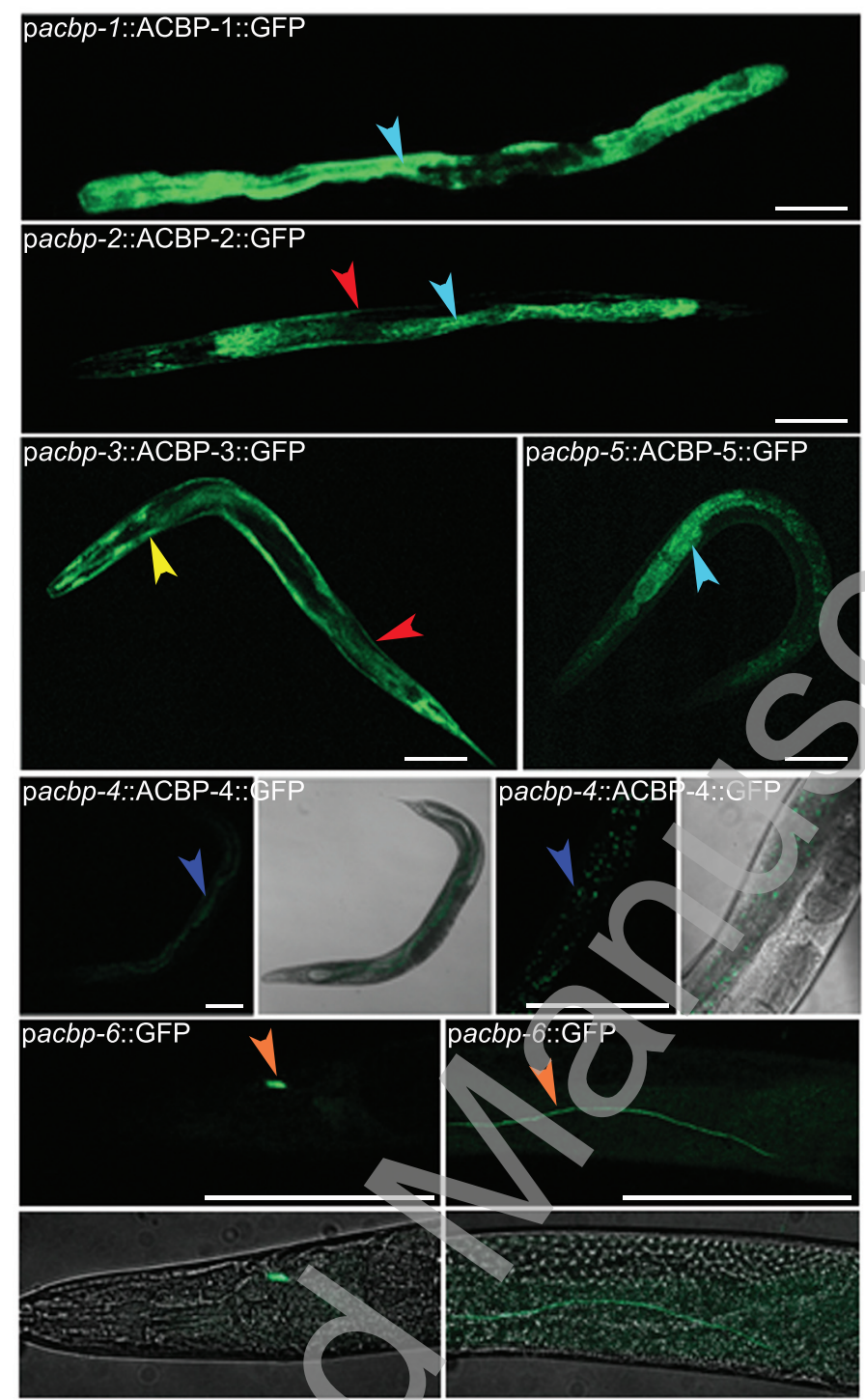

Licenced copy. Copying is not permitted, except with prior permission and as allowed by law. (c) 2011 The Authors Journal compilation (c) 2011 Portland Press Limited 
A.
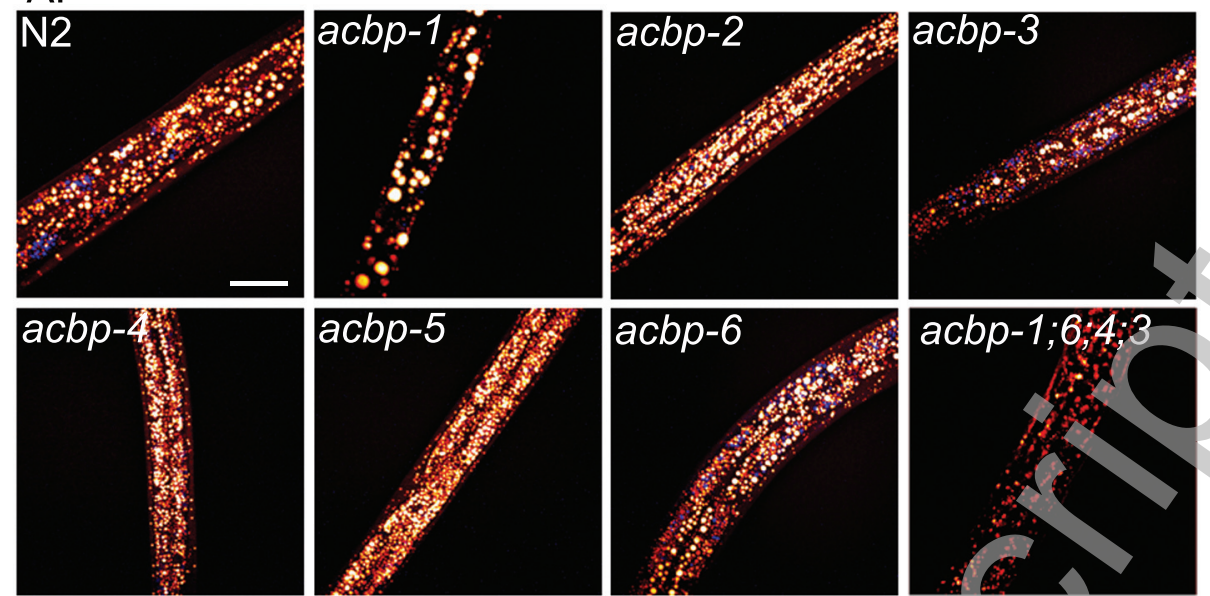

acbp-5

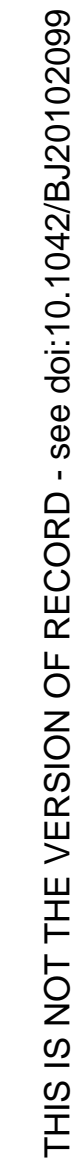
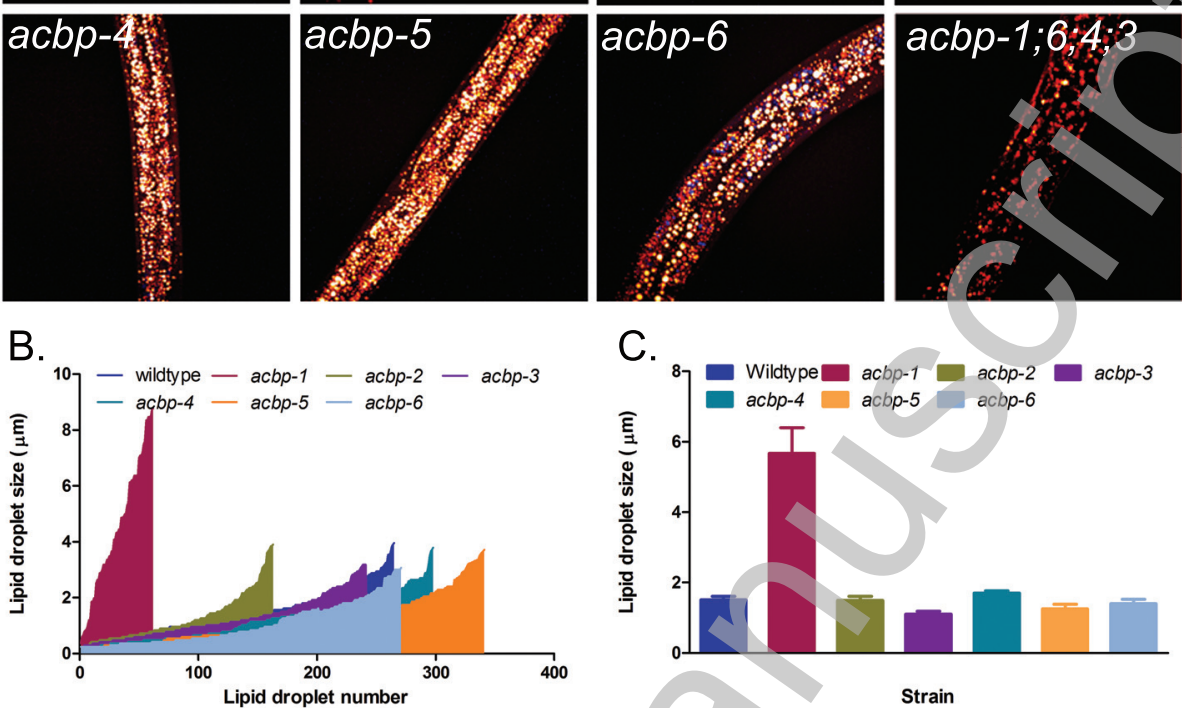

C. ${ }_{87}$ Wildtype

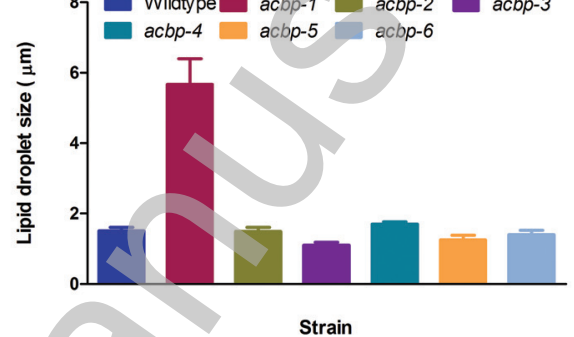

D.

E.
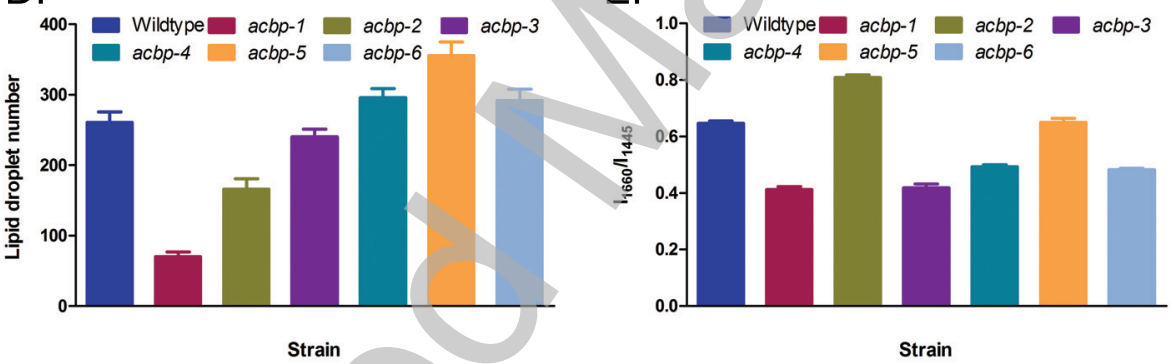

Licenced copy. Copying is not permitted, except with prior permission and as allowed by law. (C) 2011 The Authors Journal compilation (c) 2011 Portland Press Limited 
B Biochemical Journal Immediate Publication. Published on 04 May 2011 as manuscript BJ20102099

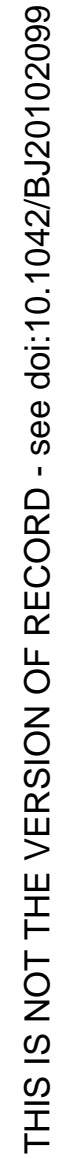

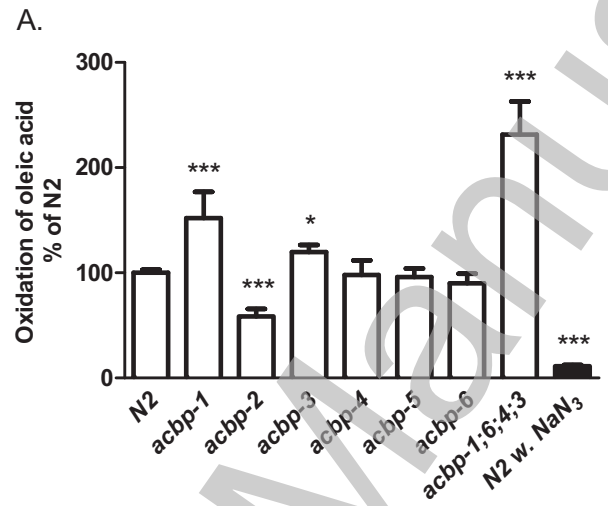

B.
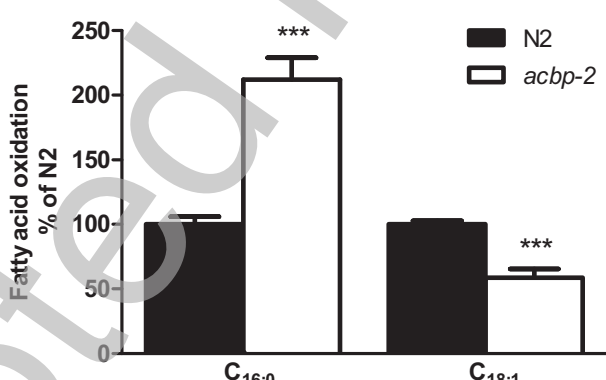

Licenced copy. Copying is not permitted, except with prior permission and as allowed by law. (C) 2011 The Authors Journal compilation (c) 2011 Portland Press Limited 


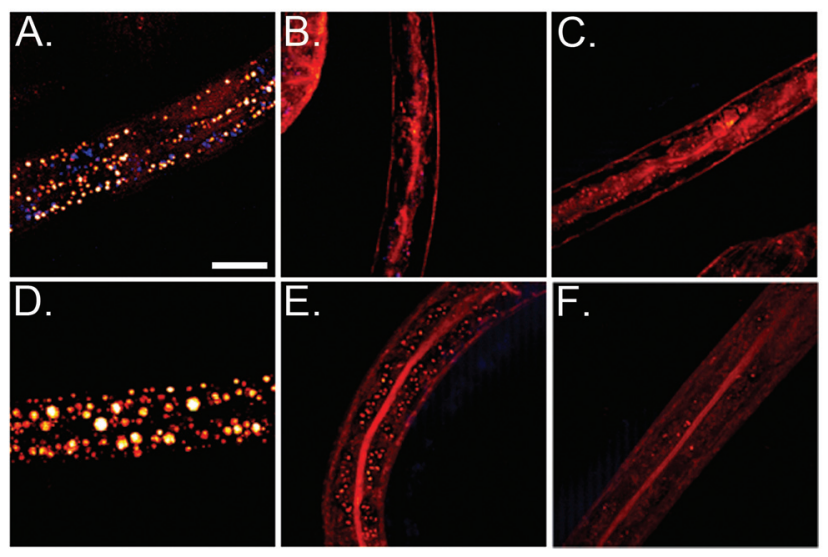

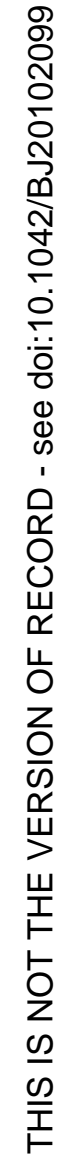

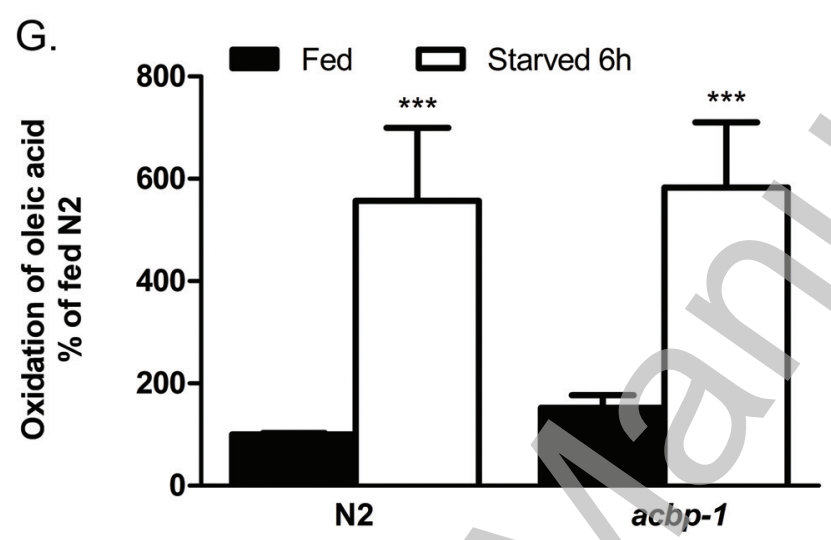

Licenced copy. Copying is not permitted, except with prior permission and as allowed by law. (c) 2011 The Authors Journal compilation (c) 2011 Portland Press Limited 